\title{
Aplikasi Multimedia Wisata Kesehatan Jamu Berbasis Android Pada desa Kalibakung Kabupaten Tegal
}

\author{
Aang Alim Murtopo \\ Email: aang.alim@gmail.com \\ TEKNIK INFORMATIKA STMIK YMI \\ Jl. Pendidikan No 1 Kota Tegal
}

\begin{abstract}
Abstrak
Perkembangan dan kemajuan teknologi telah memberikan kemudahan dalam mencari informasi yang tepat dan akurat. Khususnya aplikasi pada smartphone. Tidak sedikit dari mereka yang tidak tahu manfaat tanaman jamu untuk pengobatan alami. Hanya beberapa yang tahu akan bahaya mengonsumsi obat-obatan medis sehingga memilih untuk memakai atau mengonsumsi jamu untuk menyembuhkan luka atau penyakit yang mereka derita. Pembuatan aplikasi ini menggunakan metode MDLC (Multimedia Development Life Cycle) yang memiliki tahap Concept, Design, Collecting Materials, Assembly, Testing dan Distribution. Adobe Flash CS6 sebagai design program-nya, Adobe Photoshop CS6 sebagai design grafis-nya dan mengingat smartphone dengan salah satu sistem operasi populer yaitu android dan multimedia memungkinkan pemakai smartphone untuk memperoleh output dalam bentuk yang lebih menarik dibandingkan dengan media elektronik lain, aplikasi multimedia dapat memberikan kemudahan bagi masyarakat memperoleh informasi yang lebih jelas mengenai tanaman jamu karena penyajian informasinya ditampilkan secara multimedia, sehingga pengguna dapat mengerti gambaran atau informasi yang di inginkan. Aplikasi wisata kesehatan jamu berbasis android pada desa Kalibakung Kabupaten Tegal diharapkan dapat memberikan informasi tentang tanaman jamu dan cara mengolahnya menjadi jamu-jamuan yang dapat digunakan sebagai pengobatan alami.
\end{abstract}

Kata Kunci : MDLC (Multimedia Development Life Cycle), Smartphone, Android, Multimedia, Wisata Kesehatan Jamu.

\section{Pendahuluan}

Smartphone adalah telepon genggam yang memiliki kemampuan dengan pengunaan dan fungsi yang seperti computer. beberapa ahli mengartikan, smartphone merupakan telepon yang bekerja dengan memanfaatkan radio frekfensi dengan kata lain menggunakan jaringan nirkabel serta menggunakan seluruh perangkat lunak sistem operasi yang menyediakan hubungan standar dan mendasar bagi pengembang aplikasi, smartphone yang merupakan hasil dari perkembangan teknologi memiliki kemampuan menyajikan fitur canggih seperti surat elektronik, internet dan kemampuan membaca buku elektronik atau terdapat papan ketik (baik sebagaimana jadi maupun dihubung keluar). dengan kata lain, smartphone merupakan komputer kecil yang mempunyai kemampuan sebuah telepon Teknologi informasi.[1]

Teknologi smartphone saat ini memiliki spesifikasi perangkat keras seperti prosesor, memori, GPU, ukuran layar, jenis layar serta kamera. Sedangkan sistem operasi yang dapat dilihat antara lain Symbian OS, iOS, RIM BlackBerry, Windows Mobile, Linux, Palm, WebOS dan Android. Android dan WebOS dikularkan oleh Linux, iOS oleh BSD serta sistem operasi NeXTSTEP berhubungan dengan Unix.
Sedangkan penekanan dalam penelitian ini adalah penggunaan system operasi android.

Jamu merupakan ramuan yang berasal dari tumbuh-tumbuhan alam yang diracik tanpa menggunakan bahan kimia sebagai aditif (bahan tambahan). Jamu sering disebut sebagai ramuan tradisional karena jamu memang sudah dikenal sejak jaman nenek moyang sebelum ilmu pengetahuan yang berhubungan dengan obatobatan modern masuk ke Indonesia.[2] Kebanyakan resep racikan jamu berumur puluhan atau bahkan ratusan tahun dan terus digunakan secara turun temurun sampai sekarang ini.

Penelitian yang terkair berjudul " Jamu, Obat Traditional Asli Indonesia Sasang Surut Pemanfaatanya di Indonesia", Dijelaskan bahwa pemanfaatan jamu di Indonesia tidak konsisten dan mengalami pasang surut tergantung siapa pemegang kebijakan sehingga beberapa jamu lebih mudah dipatenkan di negara lain. Dokter sebagai pengabdi masyarakat terdepan belum secara aklamasi, menerima jamu karena ketidaktahuan atau karena pola sentral cara berpikir yang hanya terfokus pada bukti ilmiah konvensional. Untuk mengatasi masalah tersebut diperlukan beberapa alternatif yaitu pendidikan jamu secara terstruktur atau memasukkan mata ajar jamu ke dalam kurikulum pendidikan dokter dan yang paling penting adalah koordinasi dan integrasi yang saling bersinergi di antara pemegang kebijakan di 
pemerintahan, antara pemerintah dengan akademisi, pebisnis dan masyarakat serta BPOM.[3]

Penelitian terkait dengan judul Tingkat Penggunaan Jamu sebagai alternatif peggunaan obat modern pada masyarakat rendah, menengah dan keatas. Dalam penelitian ini diperoleh kesimpulan Penerimaan penggunaan jamu sebagai alternatif penggunaan obat modern pada masyarakat ekonomi rendah-menengah dan atas secara umum tinggi (58\%). Hasil tersebut peneliti kategorikan tinggi karena di tengah berkembang pesat obat modern dan era globalisasi, sebagian besar masyarakat lebih dari 50\% masih mengkonsumsi/menggunakan jamu untuk menjaga kesehatan dan menyembuhkan penyakit. Konsumsi masyarakat terhadap jamu paling tinggi adalah ekonomi rendah (pendapatan kurang dari $1 \mathrm{jt} / \mathrm{bulan}$ ), sejumlah $58 \%$ dari data responden. Masyarakat ekonomi menengah (pendapatan antara 1,5-5jt/bulan) mengkonsumsi jamu 25\% dari responden. Masyarakat ekonomi atas (pendapatan $>5 \mathrm{jt} / \mathrm{bulan}$ ) cenderung pada pengobatan farmasi (17\%). Faktor yang menyebabkan tingginya penggunaan jamu sebagai alternatif penggunaan obat modern pada masyarakat ekonomi rendah-menengah dan atas adalah faktor pribadi, faktor pemasaran, faktor sosial, faktor budaya, faktor psikologi, faktor harga, dan faktor legalitas lembaga kesehatan (rumah sakit dan puskesmas).[4]

Mengacu dari penelitian terdahulu maka melalui pengelolaan dan langkah yang tepat, jamu yang dapat dikembangkan nilai kekayaannya mampu mendorong pengembangan ekonomi nasional. Sudah tentu ada keuntungan dari pemanfaatan jamu untuk kesehatan, meski ada berbagai upaya dengan begitu banyak penelitian tentang bahan jamu atau tumbuhan yang berefek mencegah atau menyembuhkan penyakit, dan berjalannya beberapa sentral penelitian yang meneliti bahan jamu atau tanaman berkhasiat bagi kesehatan, tampaknya masih perlu didorong kearah terwujudnya jamu yang dapat digunakan masyarakat secara luas untuk kesehatan.

Kurangnya masyarakat dalam mendapatkan informasi tentang manfaat jamu. Maka tidak sedikit dari mereka yang tidak tahu manfaat dari tanaman jamu untuk pengobatan alami. Kondisi ini mengakibatkan generasi penerus bangsa dalam hal ini adalah pemuda pemudi lebih memilih obat kimka dari pada jamu. Hanya beberapa yang memang tahu akan bahaya atau efek samping mengonsumsi obat-obatan medis sehingga memilih untuk mengonsumsi jamu untuk menyembuhkan luka atau penyakit yang mereka derita.

Media informasi yang saat ini dapat di akses dengan mudah melalui smarthphone menjadi dasar untuk mengembangkan satu aplikasi berbasis android sehingga dapat mengatasi masalah tersebut diatas sehingga mampu memberikan informasi tentang jamu agar bisa mengedukasi masyarakat menjadi memahami manfaat dan pentingnya jamu untuk kesehatan. Metode pengembangan aplikasi menggunakan MDLC (Multimedia Development Life Cycle) yang memiliki tahap Concept, Design, Collecting Materials, Assembly, Testing dan Distribution. Adobe Flash CS6 sebagai design program-nya, Adobe Photoshop CS6 sebagai design grafis-nya

\section{Metodologi Penelitian}

Penelitian yang dilakukan akan bisa berjalan jika kesiapan data, jenis data yang dipakai adalah data primer dimana data ini di dapat secara langsung dari sumber yang terkait dengan wawancara dan observasi, sedangkan data sekunder didapat dari sumber lain berupa buku dan penelitian terkait.

Metode pengembangan sistem yang digunakan dalam penelitian ini adalah MDLC (Multimedia Development Life Cycle)[5]. Tahapan tahapan dalam MDLC tersusun sebagai berikut:

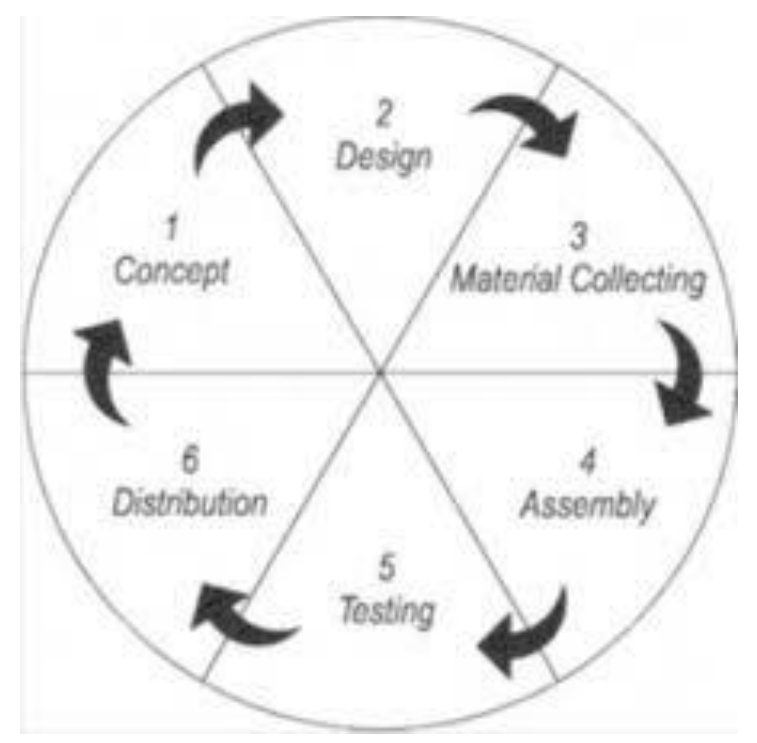

Gambar 1. Tahapan Penelitian MDLC.[5]

\section{Konsep (Concept)}

Tahap konsep merupakan tahap awal dalam siklus MDLC. Pada tahap konsep, dimulai dengan menentukan tujuan pembuatan aplikasi serta menentukan pengguna aplikasi 
tersebut. Pada penelitian ini tujuan pembuatan aplikasi ini adalah untuk memudahkan masyarakat dalam mencari informasi tanaman untuk jamu.

2. Perancangan (Design)

Tahap perancangan merupakan tahap dimana peneitian mulai di desain. Pada penelitian ini digunakan story board untuk menggambarkan cerita atau deskripsi setiap scane agar mudah dimengerti oleh setiap pengguna.

3. Pengumpulan Bahan (Material Collage)

Material Collecting adalah tahap pengumpulan bahan yang sesuai dengan kebutuhan. Bahan-bahan tersebut antara lain gambar, foto, animasi, video, audio, serta teks baik yang sudah jadi ataupun yang masih perlu dimodifikasi sesuai dengan kebutuhan yang ada.

4. Pembuatan (Asembly)

Tahap Pembuatan atau Asembly adalah tahap pembuatan keseluruhan multimedia. Pada tahap ini biasanya menggunakan perangkat lunak authoring misalnya macromedia atau adobe flash.

5. Pngujian (Testing)

Pengujian dilakukan untuk memastikan bahwa hasil pembuatan aplikasi multimedia sesuai dengan rencana. Ada dua jenis pengujian yang digunakan, yaitu pengujian alpha dan pengujian beta. Pengujian alpha seperti menampilkan tiap halaman, fungsi tombol serta suara yang dihasilkan. Jika ada malfunction maka aplikasi akan segera diperbaiki. Jika telah lolos dalam pengujian alpha maka akan dilanjutkan dengan pengujian beta. Pengujian beta adalah pengujian yang dilakukan oleh pengguna, dengan membuat kuisioner tentang aplikasi yang dibuat.

6. Distribusi (Distribution)

Tahap ini adalah tahap terakhir dalam siklus pengembangan multimedia. Pendistribusian dapat dilakukan setelah aplikasi dinyatakan layak pakai. Pada tahap ini, aplikasi akan disimpan dalam suatu media penyimpanan seperti $\mathrm{CD}$, perangkat mobile atau situds web.

\section{Hasil dan Pembahasan}

Hasil akhir dapat diperoleh dari penelitian ini adalah sebuah apalikasi yang dapat di instal pada tipe smartphone android. Animasi yang melipiputi 2 stage, stage 1 meupakan intro dan stage 2 menu utama terdiri dari sub menu diantaranya adalah sejarah, jenis Tanaman, Bantuan, Profil dan tanya aku ini dibuat meliputi 2
Tahapan pembuatan aplikasi ini dimulai dari tahap pertama (konsep) sampai dengan tahap terakhir (distribusi), dan akan dijelaskan sebagai berikut:

1. Konsep

Taahap konsep merupakan rancangan dari aplikasi yang akan dibuat, tahap ini memuat informasi yang terdapat dalam aplikasi dimana terdiri 2 scene, scene 1 intoro dimana terdapat tombol mulai, scene 2 terdiri dari tombol rofile, Bantuan, Sejarah, Jenis Tanaman, tanya aku, animasi dan keluar. Konsept ini akan memberikan kemudahan dalam tahap selanjutnya.

2. Perancangan

Dalam proses perancangan dipenelitian ini meggunakan storyboard, seperti apa yang telah di jelaskan pada tahap konsep. Berikut gambar scene 1 dan scene 2:

Scene 1 Intro terdiri dari logo, mulai digunakan untuk masuk ke menu utata, loading anaimasi untuk menampilkan animasi dan background dari intro

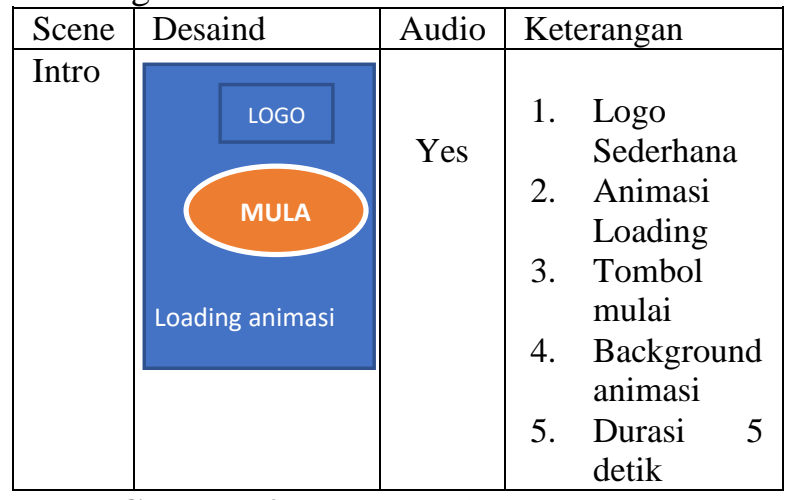

Gambar 2. Storyboard scene 1 Intro

Scene 2 Menu Utama

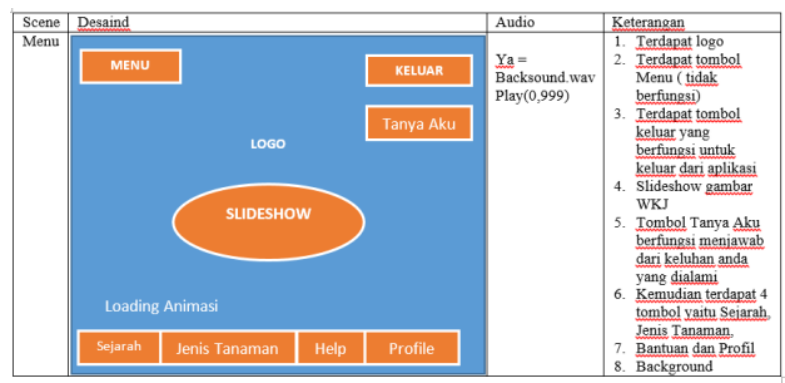

Gambar 3. scene 1 Menu Utama Aplikasi

3. Pengumpulan Bahan

Tahap ini adalah tahap dimana pengumpulan bahan bahan materi dari animasi sebagai objek animasi, audio yang berperan sebagai music dan gambar sebagai media materi materi terkait dengan jamu. 
4. Pembuatan (Asembly)

Pada tahap ini dilakukan proses pembuatan media apalikasi sesuai dengan storyboard yang telah dibuat pada tahap sebelumnya, supaya aplikasi dapat berjalan sesuai dengan yang diharapkan. Adapun hasil pembuatan aplikasi sebagai berikut:

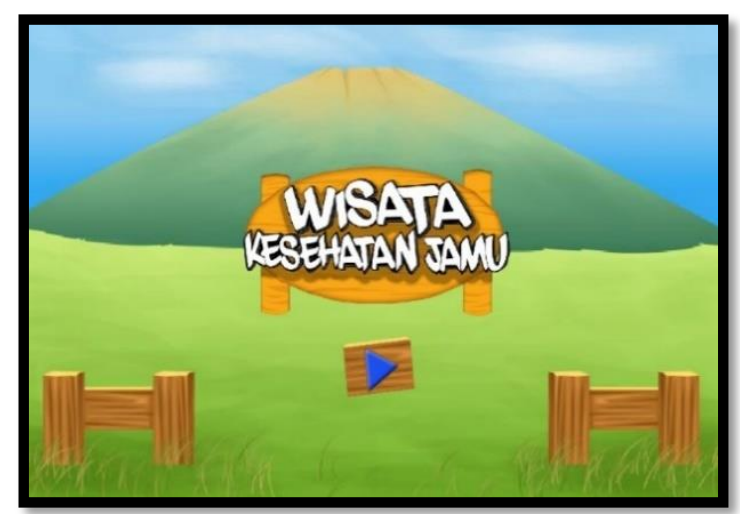

Gambar 4. Intro Aplikasi

Tampilan intro adalah tampilan awal dari aplikasi ini. Pada tampilan intro ini terdapat animasi loading dan logo beserta tombol mulai yang berfungsi untuk melewatkan intro sehingga pengguna dapat langsung menuju ke menu utama.

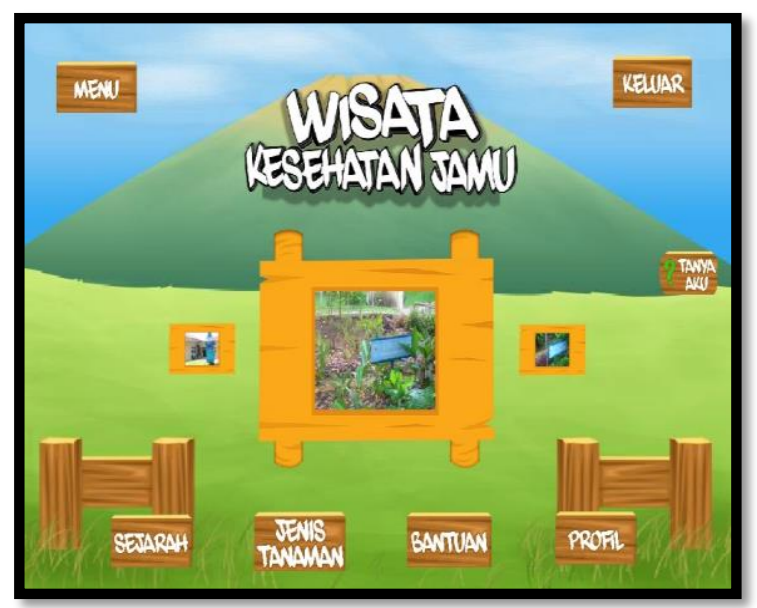

Gambar 5. Menu Utama

Tampilan Menu ini berfungsi untuk memilih sub menu apa yang akan dipilih. Gambar 5 merupakan tampilan dari menu. Di dalam menu terdapat lima tombol yang mengakses ke halaman yang berbeda dan tombol keluar untuk menutup aplikasi satu tombol menu untuk ke halaman tampilan menu. Kemudian terdapat slideshow gambar dari Wisata Kesehatan Jamu. Tombol-tombol dalam menu tersebut yaitu : Sejarah, Jenis Tanaman, Huruf Bantuan, Profil dan Tanya Aku.

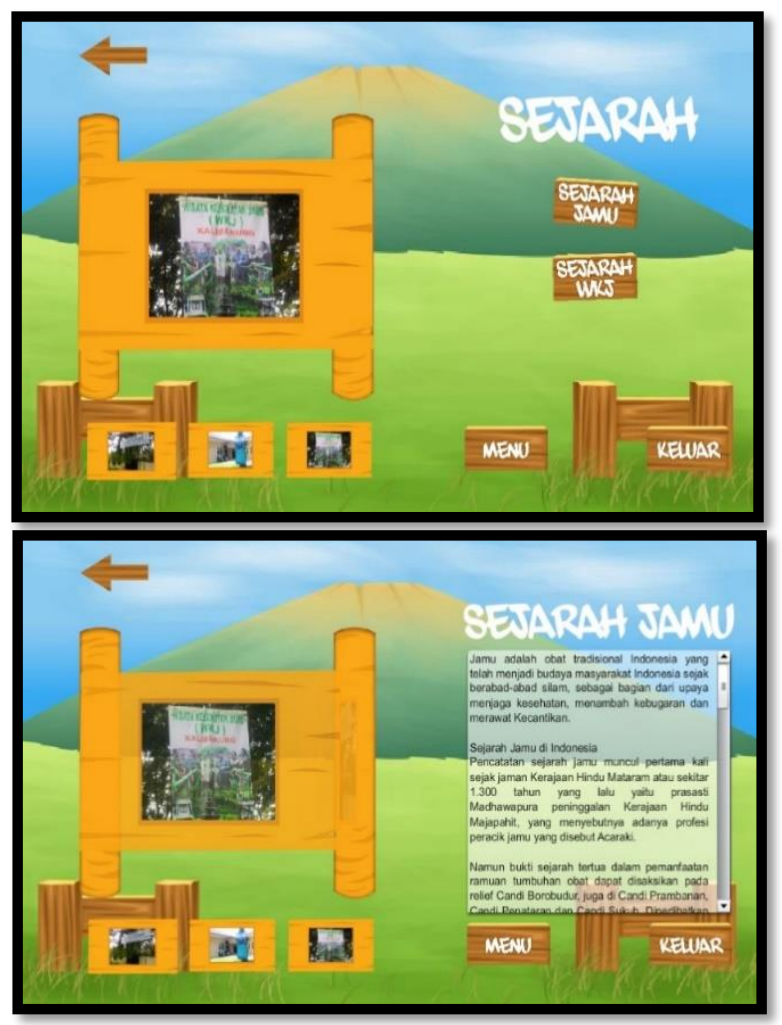

Gambar 6. Tampilan Sejarah

Di dalam halaman sejarah ini berisi tampilan yang terdapat tombol Sejarah Jamu dan Sejarah WKJ yang akan menghubungkan dengan halaman tersebut. Kemudian terdapat slideshow gambar Wisata Kesehatan Jamu. Dan terdapat juga tombol menu utama dan keluar beserta tombol kembali untuk kembali ke halaman sebelumnya.

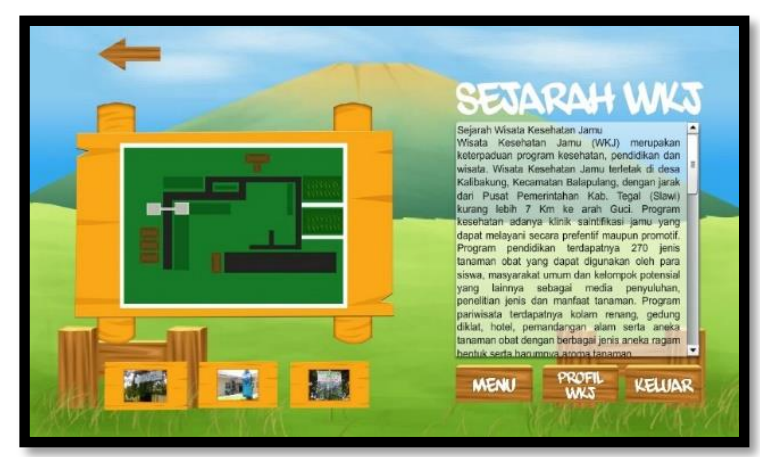

Gambar 7. Tampilan Sejarah WKS

Tampilan sejarah WKJ ini berisi scrollpane tentang sejarah WKJ beserta denah Wisata Kesehatan Jamu yang berisi tomboltombol jika ditekan akan muncul keterangan dari denah tersebut dan tombol profil WKJ untuk melihat video profil wkj. Terdapat juga tombol kembali, menu dan keluar. 


\section{Pengujian}

Pengujian white box mengasumsikan bahwa logik spesifik yang terpenting dan harus diuji untuk menjamin sistem melakukan fungsinya dengan benar. Pengujian white box adalah suatu metode desain test. Hingga proses akhir dari pengujian white box testing adalah menentukan besaran cyclomatic complexcity (cc) yang dituangkan dalam banyaknya path yang diperoleh.[6] Metode ini menggunakan notasi flow graph yang menggambarkan aliran kontrol logika yang menggunakan notasi, dalam notasi flow graph (dengan mengasumsikan bahwa tidak ada kondisi yang kompleks dalam notasi percabangan pada flowchart). Setiap lingkaran pada flow graph, disebut sebagai flow graph node merepresentasikan satu atau lebih statemen prosedural. Berikut function tampilan menu dari aplikasi wisata kesehatan jamu untuk mencari grafik alir pengujian:

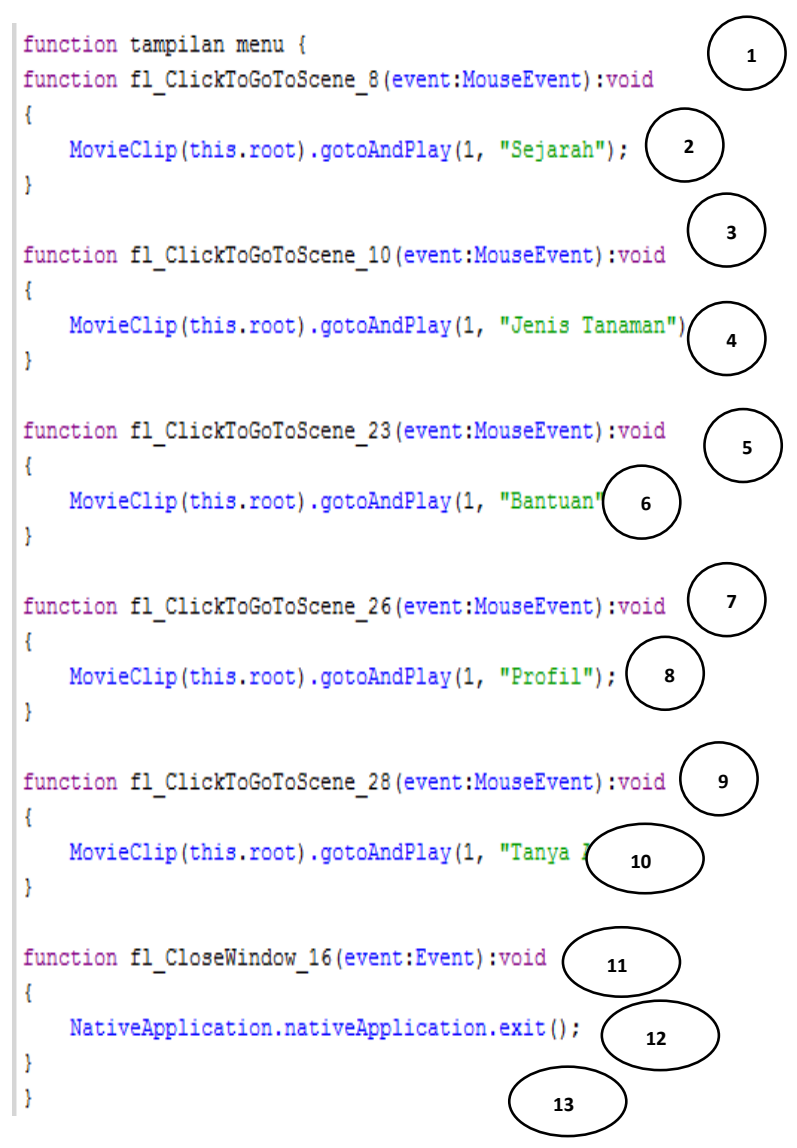

Dari code yang di uji diatas dengan meberikan node pada setiap baris code makan di dapat notasi flow Grap pada Gambar 7 berikut ini:

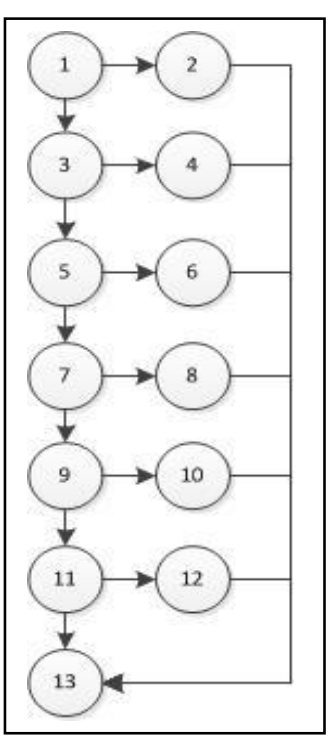

Gambar 7. Flow Grap Menu Utama Aplikasi

Cyclomatic complexcity (pengukuran kuantitatif terhadap kompleksitas logis suatu program) dari grafik alir dapat diperoleh dengan perhitungan:

Rumus :

$\mathrm{V}(\mathrm{G})=\mathrm{E}-\mathrm{N}+2$

Keterangan :

$\mathrm{E}=$ Jumlah edge atau jalur grafik alir yang ditandakan dengan gambar panah

$\mathrm{N}$ = Jumlah node atau simpul grafik alir yang ditandakan dengan gambar lingkaran

$\mathrm{V}(\mathrm{G})=$ Besaran kuantitatif terhadap cyclomatic complexcity

Cyclomatic complexcity dari grafik alir di atas adalah :

$$
\begin{aligned}
\mathrm{V}(\mathrm{G})=\mathrm{E}-\mathrm{N} & +2 \\
& =18-13+2=7
\end{aligned}
$$

Maka path yang dihasilkan yaitu 7

Path $1=1-2-13$

Path $2=1-3-4-13$

Path $3=1-3-5-6-13$

Path $4=1-3-5-7-8-13$

Path $5=1-3-5-7-9-10-13$

Path $6=1-3-5-7-9-11-12-13$

Path $7=1-3-5-7-9-11-13$

Value Test

Dari basis test yang dicoba, maka basis path 1-7 yang telah didefinisikan di atas merupakan basis set untuk grafik alir. Maka basis yang dihasilkan 13-5-7-9-11-13 terlihat bahwa simpul telah dieksekusi satu kali. Berdasarkan ketentuan dari segi kelayakan software, sistem ini telah memenuhi syarat. 


\section{Kesimpulan}

1. Aplikasi Multimedia Wisata Kesehatan Jamu Berbasis Android adalah aplikasi yang bertujuan untuk mempermudahkan wisatawan maupun masyarakat sekitar untuk mencari informasi tentang manfaat tanaman jamu sebagai pengobatan alami dengan memanfaatkan smartphone

2. Aplikasi Multimedia Wisata Kesehatan Jamu bertujuan agar masyarakat bisa memanfaatkan smartphone sebagai media informasi yang dapat digunakan untuk mengetahui definisi dan manfaat tanaman jamu sebagai pengobatan alami.

3. Menghasilkan Aplikasi Multimedia Wisata Kesehatan Jamu berbasis android dan sangat dibutuhkan karena belum adanya media informasi tanaman jamu yang efektif dan efisien di Wisata Kesehatan Jamu.

\section{Daftar Pustaka}

[1] Intan Trivena Maria Daeng, N. . Mewengkang, and E. R. Kalesaran, "91161-ID-penggunaan-smartphonedalam-menunjang-ak," e-journal "Acta Diurna," vol. 1, no. 1, pp. 1-15, 2017.

[2] J. L. Masyarakat and P. Service, "Jamu Tradisional Indonesia Tingkatkan Imunitas Tubuh Secara Alami Selama Pandemi Traditional," vol. 4, no. 2, pp. 1-7, 2020.

[3] E. H. Purwaningsih, "Jamu , Obat Tradisional Asli Indonesia Pasang Surut Pemanfaatannya di Indonesia," vol. 1, no. 2, 2013.

[4] I. Farmasi, F. Kedokteran, K. F. Kedokteran, U. Airlangga, and J. P. Moestopo, "Tingkat penerimaan penggunaan jamu sebagai alternatif penggunaan obat modern pada masyarakat ekonomi rendah-menengah dan atas Society' s acceptance level of herb as alternative to modern medicine for lower, middle , and upper class group," pp. 133145.

[5] H. Sugiarto, "Penerapan Multimedia Development Life Cycle Pada Aplikasi Pengenalan Abjad Dan Angka," IJCIT (Indonesian J. Comput. Inf. Technol., vol. Vol.3 No.1, no. 1, pp. 26-31, 2018.

[6] R. Subagia, R. Alit, and F. A. Akbar, "Pengujian white box pada sistem informasi monitoring skripsi program studi informatika," J. Inform. dan Sist. Inf., vol. 01, no. 2, pp. 539-547, 2020. 